\title{
UM DESEJO DE HISTÓRIA: A SOCIOLOGIA DO TRABALHO DE ALAIN TOURAINE (1948-1973) ${ }^{1}$
}

\section{Ricardo Colturato Festi}

é professor de Sociologia no Departamento de Humanas do Colégio Técnico de Limeira da Universidade Estadual de Campinas (Cotil-Unicamp). Campinas, SP, Brasil E-mail: <ricardofesti@gmail.com>

Orcid: 0000-0001-6360-2875

http://dx.doi.org/10.1590/0102-065096/106

Neste artigo, analiso a primeira fase da produção intelectual de Alain Touraine (1948-1973), levando em consideração que as teses desenvolvidas pelo autor em seu doutorado, defendidas em 1965, em particular a sua proposta de uma nova teoria geral sociológica - a "sociologia da ação" foram resultado de um longo processo de reflexão realizado em suas pesquisas empíricas e em seus embates teóricos no período precedente. Nesse sentido, por meio de uma ampla pesquisa em arquivos, priorizo expor os principais estudos empíricos realizados e coordenados pelo francês, buscando apontar as principais conclusões teóricas e os impactos destas em suas teses. Por fim, darei um destaque especial na relação de Touraine com a América Latina, pois as pesquisas empreendidas na região e os diálogos travados com os sociólogos latino-americanos também foram importantes na formulação de sua teoria.

\footnotetext{
${ }^{1}$ Este artigo é um desdobramento de reflexões que desenvolvi em minha tese de doutorado em sociologia, defendida em 2018, na Unicamp, intitulada $O$ mundo do trabalho e os dilemas da modernização: percursos cruzados da sociologia francesa e brasileira (1950-1960), sob orientação do Prof. Dr. Ricardo Antunes.
} 


\section{A formação sociológica de Touraine}

Touraine pertenceu à geração de sociólogos que, vindos majoritariamente da filosofia (no caso dele, da história), se formou com a prática do ofício nas décadas de 1950 e 1960, numa época em que praticamente inexistiam cadeiras de sociologia nas universidades, muito menos um curso de graduação. ${ }^{2}$ Portanto, coube a essa geração, ao mesmo tempo em que delimitava teoricamente o novo campo de conhecimento, reorganizar a sociologia na França, criando instituições de ensino e pesquisa capazes de romper com o conservadorismo das tradicionais e rígidas universidades. Foi nesse período que surgiram o Centre d'Études Sociologiques (CES), o Institut de Sciences Sociales du Travail (ISST), a VI Section de l'École Pratique des Hautes Études (EPHE) e diversos laboratórios e centros de pesquisa.

O sociólogo francês realizou seus estudos de graduação em história na prestigiosa e elitista École Normale Supérieure (ENS), vinculada à Sorbonne. Insatisfeito e incomodado com o ostracismo e o conservadorismo do corpo docente, e com a incapacidade do curso em explicar o mundo em seu processo de transformação, o jovem Touraine se afasta da instituição para conhecer de perto as experiências de implementação do "socialismo" em países do Leste Europeu. ${ }^{3}$ Ao retornar à França, abandona de vez o curso e decide se mudar para Valenciennes, em Raismes, uma cidade de operários mineiros e metalúrgicos, na divisa com a Bélgica, para trabalhar numa mina de carvão durante o inverno de 1947-1948. Em Un Désir d'Histoire, descreve com detalhes a sua estadia na região, a vida miserável e as condições de

\footnotetext{
2 A formação teórica dos primeiros sociólogos do pós-guerra ocorreu, principalmente, nos famosos seminários organizados no interior do Centre d'Étude Sociologique e nos intercâmbios de estudos nos EUA. O primeiro curso de graduação na França só foi criado em 1958.

3 Com uma bolsa de estudos, Touraine visita a Hungria e a Iugoslávia no ano de 1947.
} 
trabalho dos operários, e aponta as suas primeiras reflexões sobre a consciência operária. Essa experiência o aproximou do mundo do trabalho e da indústria, dando-lhe uma sensibilidade distinta para esta questão.

Durante essa estadia, chegou em suas mãos o livro de Georges Friedmann, Problèmes humains du machinisme industriel, que definiu o curso da sua vida:

Ele me desconcertou. Publicado em 1946, era uma obra muito nova para a França, pois a universidade francesa não se interessava pelos problemas contemporâneos do trabalho, e sobretudo do trabalho operário, objeto provavelmente muito vulgar para os nossos grandes espíritos. Friedmann foi o primeiro a estudar seriamente as usinas e a produção, a desenvolver críticas contra o taylorismo e as suas pretensões científicas. Ele evocou as objeções de fisiologistas, de psicólogos e de sociólogos; ele tentou dar uma primeira imagem da organização do trabalho através das primeiras grandes enquetes americanas, das atitudes coletivas do trabalho. Eu li este livro com exaltação. Ele falava de tudo aquilo que me interessava. Ele se aventurava longe do mundo escolar, falando de tudo o que ingenuamente eu teria chamado de "a vida". O mundo operário, ou seja, o trabalho material de produção, uma classe social e o movimento operário tinham irrompido em minha existência. Para mim, jovem burguês hiperescolarizado, a Libertação e o período de 1945-1947 (os comunistas no governo) tinham mudado tudo. Mas a irrupção de minha experiência vivida com a classe operária como realidade e como força foi mais concretamente importante. Se me tivessem pedido para desenhar a sociedade, eu teria feito em seu centro uma fábrica ou uma mina. (Touraine, 1977, pp. 44-45, tradução nossa)

A obra de Friedmann apresentava uma nova perspectiva de produção do conhecimento que parecia preencher 
a distância que separava a sua formação intelectual e o mundo do trabalho, o quartier Latin e Billancourt. "Eu não era conduzido pela teoria ou pelas hipóteses; eu queria simplesmente refletir sobre o trabalho e não mais somente sobre textos", escreveu Touraine (Touraine, 1977, p. 46, tradução nossa). Imediatamente após devorar o livro, enviou uma carta à Friedmann, que lhe respondeu calorosamente e o recomendou regressar imediatamente à Paris, terminar o curso de história na ENS e trabalhar com ele no recém-criado CES, compondo, assim, a equipe que levaria à frente as primeiras pesquisas sobre o mundo do trabalho francês.

Além da sociologia apresentar uma maior capacidade e dinâmica para analisar a realidade concreta contemporânea e de propor soluções aos problemas, a perspectiva de rápida ascensão acadêmico-profissional oferecida pela nova disciplina, desenvolvida em modernas instituições, era um forte elemento de sedução aos jovens acadêmicos. É surpreendente o quão rápido ela adquiriu prestígio e reconhecimento científico nas décadas de 1950 e 1960, um fenômeno que não esteve restrito à França. Nesse caso, vale lembrar que a sociologia se tornou uma disciplina de prestígio, com fortes vínculos com as políticas modernizadoras do país, proporcionando-lhe um significativo aporte financeiro às suas pesquisas (Tanguy, 2017).

A proposta de uma sociologia do trabalho na França foi elaborada a partir de críticas e delimitações com a sociologia industrial norte-americana, principalmente por meio das elaborações de Friedmann (1946, 1963, 1956), Touraine (1952, $1955,1961)$ e Naville $(1961,1963)$, quando ainda eram membros do CES. Todavia, esse processo não se tratou de um distanciamento no âmbito puramente teórico, pois as pesquisas empíricas dirigidas por esses autores ao longo dos anos 1940 e 1950 os fizeram confrontar as teses da sociologia industrial com a realidade concreta do mundo industrial francês.

Touraine (1952) afirma que a sociologia industrial norte-americana refletia o próprio desenvolvimento das relações 
entre capital e trabalho, e também a tradição do movimento operário norte-americano, ou seja, um movimento sindical de pressão e reformista. Estes tinham como prática isolar os problemas internos à empresa e abrir mão de uma ação transformadora da sociedade. Portanto, a mais marcante de suas características era o rol passivo dos operários na valorização de seu trabalho. Nesse contexto,

não é o operário, o movimento operário, independente de qual ele seja, quem define as condições desta valorização, mas os psico - ou sociotécnicos - quem consideram o meio social da fábrica como um terreno de experiências e aceitam intervir sobre os quadros impostos pela empresa. (Touraine, 1952, p. 165, tradução nossa)

Assim, a Human Relations, principal base teórica da sociologia indústria norte-americana, se propunha a substituir as ações espontâneas dos trabalhadores por uma sociologia intervencionista ou, na expressão de Roethlisberger (1941, tradução nossa), por "médicos da sociedade", criando, como bem destacou Braverman (1987), não uma ciência social, mas tão somente um ramo da ciência gerencial.

Diante de um movimento operário de tradição combativa e revolucionária, seria impossível a construção de uma "ciência gerencial" na França, baseada em um modelo teórico em que a fábrica era compreendida enquanto um sistema fechado. O estrutural-funcionalismo era, portanto, descartado. Em seu lugar, os franceses buscaram construir uma sociologia que explicasse a realidade concreta a partir de sua totalidade e historicidade. Portanto, ela deveria ser "considerada, em sua dimensão mais vasta, como o estudo, em seus diversos aspectos, de todas as coletividades humanas que se constituem à ocasião do trabalho" (Friedmann e Naville, 1961, p. 89, tradução nossa).

Nesse sentido, os franceses propuseram um novo domínio das ciências sociais, estruturado em estudos 
interdisciplinares sobre o mundo do trabalho, reforçando um diálogo com a psicologia social, a economia, a demografia, a etnologia e a história do movimento operário. Entendiam que a sociologia do trabalho não teria uma fronteira rigorosamente delimitada, já que o trabalho seria uma das questões centrais para compreender o conjunto da sociedade.

Isto permitiu a produção de uma heterogeneidade de pesquisas e interpretações sobre o mundo do trabalho ao longo das décadas de 1950 e 1960, a partir de um amplo leque de temas, como as atitudes e a consciência operárias, a mobilidade social e profissional dos trabalhadores, os impactos sociais das transformações tecnológicas, as formas de organização das empresas, o sindicalismo, entre muitos outros. O momento áureo da institucionalização desse novo domínio foram as publicações do primeiro volume da famosa revista Sociologie du Travail, em 1959, e dos dois

70 volumes do Traité de Sociologie du Travail, organizados por Friedmann e Naville, em 1961 e 1962.

\section{Projeto de tese sobre consciência operária, trabalho e ação social}

Em 1953, após realizar um estágio de estudos de um ano nos EUA - financiado pela fundação Rockefeller - e antes de retornar a Billancourt para coletar novos dados ao livro que publicaria dois anos mais tarde, Touraine apresentou um projeto de pesquisa para um doutorado de Estado em Letras, com os temas "A consciência de classe e a ação operária" (tese principal) e "O trabalho e as classes sociais" (tese secundária). Dez anos depois, quando finalmente defendeu a sua tese, os títulos finais ficaram "Sociologia da ação Social" e "A consciência operária".

Ao longo desse intervalo, entre o depósito do projeto e a defesa da tese, o autor se manteve dentro de um mesmo campo de reflexão teórica, abordando um conjunto 
delimitado de problemáticas, embasadas, principalmente, em suas pesquisas empíricas. Em seus relatórios de avaliação encaminhados ao Centre National de la Recherche Scientifique (CNRS),${ }^{4}$ Touraine aponta o desejo de realizar pesquisas que buscassem uma relação entre os temas da sociologia industrial e a sociologia das classes sociais pois, segundo sua perspectiva, os dois abordavam os mesmos problemas sobre o trabalho, a significação social deste e a unidade de seus diversos aspectos. ${ }^{5}$

Tratava-se, portanto, de um projeto de enorme envergadura que implicava certas condições financeiras e estruturais que só foram possíveis de serem obtidas graças à estrutura criada pelas novas instituições de ensino e pesquisa na França. Além disso, o autor soube muito bem aproveitar as demandas vindas de organismos nacionais e internacionais, como a Organização Europeia de Cooperação Econômica (OECE) e a Fundação Rockefeller, em benefício de suas pretensões. É interessante perceber, ao ler os relatórios finais dessas pesquisas empíricas, uma tensão entre uma análise objetiva e técnica sobre os impactos da aceleração da produtividade do trabalho, aos moldes das exigências das agências financiadoras, e uma análise crítica e autônoma dos resultados dessas políticas. É verdade que havia uma aproximação entre as políticas modernizadoras e o projeto de uma sociologia socialdemocrata, ${ }^{6}$ mas isso não implicava uma adesão acrítica desta àquela.

Em 1953, diante desse novo meio acadêmico em formação, o jovem Touraine via a oportunidade de iniciar um grande projeto de reflexão teórica que pudesse aportar com uma nova teoria sociológica geral. Recém-chegado dos

\footnotetext{
${ }^{4}$ Cf. Dossier de carrière: Alain Touraine, Centre national de la recherche scientifique (CNRS). Archives Nationales (France). Código: 910024 DPC.

${ }^{5}$ Cf. Dossier de carrière: Alain Touraine, CNRS, Archives Nationales (France). Código: 910024 DPC.

${ }^{6}$ Cf. entrevista com Touraine, realizada por mim, em 22 fev. 2017.
} 
EUA, o autor francês tinha a pretensão de superar a sociologia industrial norte-americana e formular uma nova teoria sociológica em deliberado debate com Talcott Parsons, autor em voga e representante máximo do estrutural-funcionalismo daquele momento. De acordo com que se recorda Cardoso, Touraine "queria fazer uma nova teoria da ação". ${ }^{7}$ $\mathrm{O}$ mundo do trabalho, que naquele momento era o fator central da sociedade francesa, seria o ponto de partida da reflexão tourainiana.

\section{As primeiras grandes pesquisas empíricas de Touraine}

Nesta parte do artigo, apresento os objetos, os métodos e algumas das conclusões centrais de Touraine em duas pesquisas empíricas realizadas durante o seu período de formação enquanto sociólogo. As preocupações com as consequências das transformações técnicas sobre o trabalho e a sociedade expressavam uma ainda forte influência de

72 Friedmann em seu trabalho. No entanto, indo além de seu mestre, Touraine se preocupou também em compreender, por meio de pesquisas de opinião sobre as orientações e a consciência do operário, a ação social dos sujeitos e a implicação disso na formação da sociedade moderna.

\section{A evolução do trabalho nas fábricas Renault}

A pesquisa que Touraine empreendeu nas fábricas Renault foram realizadas, essencialmente, entre 1948 e 1949, sob a direção de Friedmann, financiamento do CES-CNRS, e complementadas por novas pesquisas empíricas em 1951, 1952 e 1954. Com elas, Touraine obteve o diploma de Estudos Superiores em História (hoje, equivalente ao mestrado) em 1949 e, posteriormente, em 1955, publicou o livro L'évolution du travail ouvrier aux Usines Renault.

${ }^{7}$ Cf. entrevista com Fernando Henrique Cardoso, realizada por mim, em 6 dez. 2017. 
O autor analisa as relações industriais sob a ótica da observação histórica, buscando alargar a perspectiva dada até então pela sociologia industrial norte-americana aos estudos similares. Com isso, encontrou, no complexo de fábricas da Renault, o que considerou como a manifestação das sucessivas etapas da evolução técnica da indústria francesa desde a primeira guerra mundial (Touraine, 1955). O foco da investigação era a relação entre a máquina e o homem. Sua explicação sobre a evolução da técnica e das categorias profissionais, no entanto, se pautou em elementos históricos e macrossociais, o que o levou à compreensão de que a técnica é um desdobramento do modelo econômico adotado, e não o contrário. "Se as descobertas técnicas produzem transformações econômicas, elas se explicam, por sua vez, pelas condições do mercado, dos produtos e da mão de obra, pelas exigências de uma situação econômica" (Touraine, 1955 , p. 10, tradução nossa). Ou seja, teria sido a necessidade de um crescimento econômico acelerado no período do pós-guerra na França, pautado no desenvolvimento industrial, que conduziu a adoção de novas técnicas e de um novo maquinário, tendo, com isso, um desdobramento nos aspectos profissionais.

Touraine encontrou nas oficinas da Renault dois departamentos completamente diferentes quanto à técnica e à organização do trabalho. O primeiro fabricava peças para diversos motores e tinha máquinas ultrapassadas, oficinas com chaminés e estoques amarrotados. $\mathrm{O}$ segundo era um galpão consagrado somente à fabricação do modelo do carro 4CV, com máquinas modernas e um estoque reduzido. Esses dois departamentos representavam, na análise de Touraine, a diferença entre a velha fábrica do pré-guerra daquela que viria a dominar o cenário fabril francês. Podia-se verificar, nessa fase de transição pela qual passava a economia industrial, a "degradação massiva do trabalho" e o surgimento de um "operário especializado" 
em todos os locais em que se instalava a produção em série ${ }^{8}$ (Touraine e Verley, 1949).

Para explicar esta passagem de um sistema de trabalho qualificado para um de trabalho especializado ou de um sistema profissional para um sistema técnico de trabalho, Touraine constrói um quadro descritivo conforme as situações encontradas nas oficinas da Renault, dividindo o desenvolvimento da indústria na primeira metade do século XX, em três fases distintas. A primeira, a Fase A, seria o antigo sistema e se caracterizaria pelo trabalho qualificado e pelas máquinas universais e "flexíveis". Em seguida, a Fase B, período de transição, se caracterizaria pelo desenvolvimento do maquinismo e pelo trabalho especializado ou não qualificado de alimentação das máquinas. Essa seria a fase em que a produção é organizada pelo taylorismo-fordismo. Por último, a Fase C seria a do automatismo, das máquinas especializadas complexas, e da eliminação do trabalho diretamente "produtivo" (manual).

A passagem para a Fase $\mathrm{C}$ teria criado uma grande reviravolta na história do trabalho, pois nessa se criou um novo tipo de operário, de relação de trabalho e de relação entre a produção e a sociedade. Com máquinas especializadas complexas ou máquinas automáticas, a produção passou a ser realizada em fluxo contínuo. O operário tornou-se um controlador de máquinas ou um supervisor de sistema. "Neste estágio, a qualidade do operário não é mais definida a partir das condições técnicas do trabalho, mas a partir de suas condições sociais" (Touraine, 1955, p. 177).

${ }^{8}$ No caso das usinas Renault, o departamento de ferramentaria, onde se exigia um trabalho mais "artesanal", $38,2 \%$ dos trabalhadores eram não qualificados e $61,8 \%$ qualificados. Já na linha de montagem do departamento de usinagem, onde se empregava máquinas mais modernas, $82,6 \%$ eram não qualificados e somente $17,4 \%$ qualificados (Touraine e Verley, 1949). 
Na Fase C é necessário um clima de colaboração para a eficácia do processo de produção. O empregador busca o espírito de controle, o sentido de responsabilidade, mais que uma habilidade ou um savoir-faire. Suas capacidades manuais são menos importantes que as suas atitudes em exercer com seriedade, inteligência e precisão uma determinada tarefa. Em efeito, a qualificação dos operários é constituída de "competências técnicas e inseparavelmente de qualidades sociais, ou seja, de sua atitude a ocupar um lugar determinado numa organização à sua vez técnica e social" (Touraine, 1955, p. 54).

A substituição do operário qualificado - que tinha na destreza, no saber empírico e na experiência as suas vantagens e utilidades para o processo de trabalho - por um operário especializado (não qualificado), num amplo processo de fragmentação das operações, teria tido um efeito sobre a consciência operária. O típico operário do século XIX, segundo Touraine (1955), se constituía como uma classe social que colocava uma nítida barreira social entre a sua cultura e o resto da sociedade e, portanto, o antagonismo de classe era muito mais evidente. Com o desenvolvimento do maquinismo ao longo da primeira metade do século XX, as "barreiras" que evidenciavam as diferenças entre as classes tendem a ficar ofuscadas com o desenvolvimento do consumo e da cultura de massa difundida pelos grandes meios de comunicação (jornal impresso, cinema, rádio, televisão). Ao mesmo tempo, no interior da fábrica, a alienação tende a avançar, com o operário perdendo a dimensão da totalidade do processo de trabalho. Por isso que, na Fase C, são as questões sociais, mais que as profissionais, que ganham relevância para a definição da força de trabalho.

\section{Projeto 164 e as atitudes operárias}

Um dos mais importantes projetos europeus de pesquisa sobre o mundo industrial na década de 1950 foi o Projeto 
164, que teve como tema central "As atitudes dos trabalhadores em relação às transformações técnicas da indústria do aço". Financiado pela Agência Europeia de Produtividade, setor da OECE, e as comissões nacionais de produtividade, ele foi concretizado por seis institutos de pesquisa de seis diferentes países do velho continente. No caso da França, a pesquisa ficou a cargo do ISST e a direção de Jean Daniel Reynaud (ISST) e Alain Touraine (EPHE). ${ }^{9}$

A ideia desse estudo surgiu da convicção de que era tempo de realizar uma pesquisa mais sistemática sobre a adaptação ao progresso técnico desde os pontos de vistas da organização e do indivíduo em um dos ramos em que ele aparece: a siderúrgica. O crescimento da produção de aço afeta diretamente os desenvolvimentos técnicos e um tal crescimento não seria possível sem inovações técnicas, portanto esperamos concentrar a atenção dos pesquisadores nos problemas referentes à adaptação na indústria do aço. ${ }^{10}$

O projeto vigorou de 1954 a 1957 e foi executado em duas etapas. Cada estudo levou em consideração os fatores sociais internos e externos às fábricas, o processo de trabalho, o peso e o papel dos sindicatos, a política salarial e de promoção, a qualificação e a formação dos operários, entre muitos outros aspectos. Eles compreendiam tanto uma descrição das transformações técnicas ocorridas nas fábricas e as suas consequências sobre o trabalho (aspectos objetivos), quanto uma análise da percepção dessas transformações pelos trabalhadores (aspecto subjetivo).

9 Trabalharam enquanto pesquisadores, durante a primeira fase do estudo, Jacques Dofny e Bernard Mottez, com ajuda de Adrien Morel; e durante a segunda fase, Claude Durand, Paul Pascon e Philippe Pigelet, com ajuda de Térence Maranta.

${ }^{10}$ Cf. "Attitudes des ouvriers de l'industrie sidérurgique à l'égard des changements techniques : une étude pilote. Confidentiel. Rapport de l'étude pilote". Projet 164 Recherche en sociologie industrielle. Juin 1955-juin 1959. Arquivos da OCDE, Paris. Microfilme: OCDE 83. 
A equipe do ISST escolheu como campo de pesquisa uma tôlerie ${ }^{11}$ da cidade de Mont-Saint-Martin, localizada na bacia siderúrgica de Longwy, região de Lorena, no Leste da França e no limite fronteiriço com a Bélgica e Luxemburgo. A fábrica escolhida, uma dentre as quatro principais produtoras de aço do país, tinha ao redor de 5.000 operários e instalaria, em agosto de 1955, um novo laminador de chapas (plate mill).$^{12}$ Isso daria aos pesquisadores a oportunidade, diferente dos outros institutos envolvidos na pesquisa, de avaliar as atitudes dos operários na alteração do maquinismo, captando as opiniões dos operários antes e depois das mudanças, destacando as suas expectativas e julgamentos.

Nove anos após a publicação do relatório final (1957) do Projeto 164 na França, Touraine escreveu uma nova conclusão para a publicação de 1966 do ISST (Dofny et al., 1966). Nesse novo livro, ele submete as análises empíricas realizadas quase uma década antes ao esquema teórico defendido em sua tese, buscando generalizar as conclusões da pesquisa e colocá-las sob uma perspectiva histórica. "Este modo de análise conduz, na prática, a problematizar sobretudo as formas de introdução da mudança, ou seja, da gestão dos desequilíbrios necessários introduzidos pela inovação" (Dofny et al., 1966, p. 241, tradução nossa), ressalta.

Sua exposição parte de categorias duais para explicar as transformações ocorridas nas atitudes e na consciência operárias. $\mathrm{O}$ antigo centro industrial, a siderúrgica, dominado por um tipo de trabalho, de relações sociais e condições de existência tradicionais é substituído por uma instalação muito mais moderna. Dessa forma, distanciando-se dos casos

\footnotetext{
11 Em francês, tôlerie é a fabricação, o trabalho ou o comércio de tôle. É também o local em que se trabalha a tôle. Tôle é a chapa de ferro ou de aço obtida pela laminação.

12 Uma das grandes alterações ocorrida na fábrica selecionada foi a instalação de uma linha de produção. Todo o maquinário foi substituído por novos fornos, prensas e laminadores etc.
} 
estudados, o autor considera possível generalizar a mudança de atitude vivida pelos operários como um exemplo vivo da experiência de redescoberta pela sociedade francesa da expansão (econômica). "De fato, a mudança observada nos informa historicamente mais que as crises vividas pelos setores arcaicos, porque a economia francesa, durante o período estudado, está em expansão” (Dofny et al., 1966, p. 242).

Após a modernização da fábrica, um quadro novo de referências aparece: a organização racional da empresa. Esta serviria a toda uma linguagem comum, que pode servir tanto ao conflito quanto à negociação. A ideia de que o nível salarial depende antes de tudo da ação coletiva dos trabalhadores é predominante, "mas os operários da nova tôlerie aprenderam a definir sua situação, seus interesses, seu adversário em termos mais concretamente econômicos" (Dofny et al., 1966, p. 247). Disso desdobra sua principal conclusão:

Antes da mudança, a empresa é o lugar onde se manifesta a contradição fundamental do trabalho e do dinheiro; após, ela é conhecida como um campo de ação onde os trabalhadores encontram novos meios de defender sua reivindicação. Com a modernização, passamos da ruptura ao conflito. (Dofny et al., 1966, p. 247)

\section{As pesquisas no Laboratório de Sociologia Industrial}

$\mathrm{O}$ Laboratoire de Sociologie Industrielle (LSI) foi criado em janeiro de 1958 por iniciativa de Fernand Braudel, presidente da VI Sessão da EPHE, e de Friedmann. Dois anos depois, a direção deste novo laboratório passou para as mãos de Touraine. Ele havia deixado o CES e o CNRS em 1958 para ingressar na EPHE, vinculando-se, desde o início, ao LSI. As alterações nos eixos e temas de pesquisas ao longo de sua curta e promissora história coincidem com os mesmos movimentos que o sociólogo francês realizou em sua obra. Tanto em um 
quanto em outro, aflorava uma vontade de compreender a nova sociedade que emergia, aventurando-se em temas que transbordavam o âmbito da indústria e do trabalho. Este movimento levou, após as rebeliões de 1968, à alteração do nome do laboratório para Centre d'Études des Mouvements Sociaux (CEMS) em 1970, consolidando, assim, o início de uma nova fase centrada nos estudos sobre os movimentos sociais.

A criação do LSI pode ser considerada como parte da evolução que vinha ocorrendo na própria EPHE. Ele teve como objetivo principal e fundador reunir e associar um certo número de pesquisadores orientados para os mesmos problemas e "desejosos de desenvolver um conjunto coerente de proposições teóricas e de elevar o nível técnico e metodológico de suas pesquisas" (Le Laboratoire de Sociologie Industrielle de L'école..., 1960, p. 218). Nessa perspectiva, os interesses do grupo estavam para além de compreender a sociedade francesa ou os temas exclusivamente vinculados ao trabalho. Interessavam-se "do sindicalismo francês aos nacionalismos latino-americanos, da mobilidade social à urbanização, do hospital às relações de classe" (Le Laboratoire de sociologie industrielle, 1966, p. 1).

Segundo o relatório de atividades do LSI de 1966, a inspiração inicial do laboratório era "refletir metodologicamente sobre a razão de ser das sociedades industriais ou em via de industrialização; compreender como as sociedades inventam sua história, por meio dos movimentos sociais, a dinâmica das organizações, os projetos pessoais" (Le Laboratoire de sociologie industrielle, 1966, p. 1). ${ }^{13} \mathrm{O}$ Quadro 1 nos fornece um panorama das pesquisas realizadas pelo LSI. Se acompanharmos a sua evolução ao longo da década de 1960, fica claro um deslocamento das preocupações do grupo com as temáticas sobre o mundo industrial e do trabalho para as relacionadas

13 Cf. Rapport d'activité du laboratoire de sociologie industrielle, 1966, p. 1. Arquivo da EHESS, Paris. Código: CEMS1. 
ao desenvolvimento, em particular ao processo de industrialização de países periféricos, e às esferas sociais e políticas que passaram a ter relevância no mundo ocidental, como foi o caso das universidades e do movimento estudantil.

Quadro 1

Principais pesquisas realizadas no LSI entre 1958 e 1969

\begin{tabular}{|c|c|c|c|}
\hline Eixo central & Tema & Período ${ }^{15}$ & Pesquisadores \\
\hline \multirow{4}{*}{$\begin{array}{l}\text { Atitudes no trabalho e } \\
\text { consciência operária }\end{array}$} & A consciência operária & 1958-1964 & Alain Touraine \\
\hline & $\begin{array}{c}\text { Atitudes no trabalho e } \\
\text { projeto pessoal }\end{array}$ & $1958-1960$ & $\begin{array}{c}\text { René Bassoul, Pierre } \\
\text { Bernard, AlainTouraine }\end{array}$ \\
\hline & $\begin{array}{c}\text { Os operários de origem } \\
\text { agrícola }\end{array}$ & 1958-1964 & $\begin{array}{l}\text { Alain Touraine e } \\
\text { Orietta Ragazzi }\end{array}$ \\
\hline & $\begin{array}{l}\text { Os operários, a } \\
\text { mobilidade e o } \\
\text { desenvolvimento } \\
\text { econômico }\end{array}$ & $1958-1966$ & Lucien Karpik \\
\hline 0 sindicalismo & 14 & $1958-1966$ & $\begin{array}{c}\text { Claude Durand, Sabine } \\
\text { Erbès-Seguin, Daniel Vidal, } \\
\text { Eliane Baumfelder }\end{array}$ \\
\hline $\begin{array}{l}\text { Problemas urbanos e } \\
\text { regionais }\end{array}$ & $\begin{array}{c}\text { As decisões da } \\
\text { localização industrial }\end{array}$ & $1958-1966$ & $\begin{array}{c}\text { Touraine, Vito Ahtik, } \\
\text { Sylvia Zygel e } \\
\text { Manuel Castells }\end{array}$ \\
\hline $\begin{array}{c}\text { Desenvolvimento } \\
\text { econômico (mudanças } \\
\text { sociais) e movimentos } \\
\text { sociais na América } \\
\text { Latina } \\
\end{array}$ & 14 & $1965-1969$ & $\begin{array}{l}\text { Touraine, D. Pécaut, M. } \\
\text { Pécaut, Bernard M ottez, } \\
\text { Cecilia Sella, Roberto de } \\
\text { Las Casas e Esteban Pinilla } \\
\text { de Las Heras, G. de Sierra }\end{array}$ \\
\hline $\begin{array}{c}\text { Novos aspectos das } \\
\text { estruturas sociais na } \\
\text { França }\end{array}$ & 14 & 1966- & $\begin{array}{l}\text { Karpik, Touraine, } \\
\text { Ahtik, Amiot }\end{array}$ \\
\hline $\begin{array}{c}\text { Organizações e } \\
\text { empresas }\end{array}$ & & 1966- & Bernard Mottez \\
\hline $\begin{array}{c}\text { Organização } \\
\text { universitária e } \\
\text { movimento estudantil }\end{array}$ & 14 & $1967-1969$ & $\begin{array}{l}\text { N. Abboud, S. Bosc, G. Le } \\
\text { Maitre, L. Maheu, } \\
\text { C. Zaidman }\end{array}$ \\
\hline
\end{tabular}

Fonte: Elaboração própria. Tabela baseada nas informações Le Laboratoire de sociologie industrielle $(1966,1969)$.

14 Ocorreram várias pesquisas temáticas que não foram especificadas na tabela.

15 Não foi possível precisar a data de término de algumas pesquisas. 
Nos primeiros anos e até meados da década de 1960, o LSI se concentrou nos estudos sobre a classe operária e o processo de industrialização, em particular sobre as atitudes e a consciência dos operários frente ao trabalho e suas transformações técnicas e organizacionais. Essas pesquisas seguiam o mesmo universo de preocupação inaugurada pelas investigações conduzidas por Friedmann no CES, mas a abordagem agora visava explorar muito mais as experiências dos operários em seu trabalho do que as consequências das transformações técnicas sobre eles. $\mathrm{O}$ modelo seguido era o das enquetes levadas à frente pela Survey Research Center da Universidade de Michigan, onde Touraine havia estabelecido contato em um de seus intercâmbios nos EUA. Os resultados parciais ou finais eram expostos por meio de seminários, organizados no interior do laboratório, dando ênfase às discussões sobre as elaborações teóricas relativas aos temas abordados nas pesquisas como também a apresentação de novos métodos e técnicas de investigação.

Nas pesquisas organizadas em torno do eixo "Atitudes no trabalho e consciência operária”, vale destacar os temas sobre a "consciência operária" e sobre "os operários de origem agrícola”. A primeira teve início em 1956 no CES, com aportes financeiros da Fundação Rockefeller, e foi levada para o LSI após sua fundação. Ela envolveu mais de 50 pessoas, entre pesquisadores, funcionários e estagiários, sendo que foram aplicados questionários com 2002 operários de 80 diferentes departamentos, 200 aglomerações e 400 estabelecimentos em toda a França. O objetivo era compreender a experiência social no trabalho a partir da percepção dos próprios operários, alimentando a perspectiva de ação social e de sujeito histórico que Touraine vinha desenvolvendo. Essa pesquisa foi a principal fonte para a elaboração de sua tese secundária, defendida em 1965, La conscience ouvrière.

A segunda pesquisa a destacar estudou os operários de origem agrícola. Tratava-se de compreender como as 
atitudes dos operários urbanos em relação a sua nova situação social eram determinadas pela experiência de mobilidade (êxodo rural). A conclusão era que "a consciência de ascensão social própria àqueles que conseguiram penetrar na economia industrial e urbana favoriza a sua vez um optimismo considerável e uma marginalidade em relação à situação de trabalho" (Touraine e Ragazzi, 1961, p. 117, tradução nossa). Portanto, não existiria um choque com o trabalho industrial, pois ele era percebido como uma promoção e como uma etapa de curta duração. O resultado dessa pesquisa foi publicado em 1961, no livro Ouvriers d'origine agricole.

Outro tipo de pesquisa que foi marcante no LSI era relacionada às relações político-acadêmicas que Touraine e seu grupo estabeleceram com vários institutos e universidades da América Latina. Elas tiveram início em 1958, ano de fundação da LSI, menos de um ano após o retorno do sociólogo

82 francês de sua estadia em Santiago do Chile para dirigir uma pesquisa sobre sociologia industrial. A confrontação e a comparação entre as sociedades de capitalismo avançado e a periferia era um elemento fundamental para o desenvolvimento e o amadurecimento da teoria de Touraine. Além disso, era também uma oportunidade de empreender pesquisas empíricas, contando com incentivos financeiros de organismos nacionais e internacionais que tinham como preocupação o desenvolvimento do "terceiro mundo", e de se vincular aos jovens sociólogos latino-americanos que despontavam em meio a uma recém-criada estrutura acadêmica em seus países.

\section{A América Latina enquanto encruzilhada da modernização}

É amplamente conhecido que Touraine manteve uma profunda relação pessoal, ${ }^{16}$ intelectual e profissional com a

\footnotetext{
${ }^{16}$ Foi durante esta estadia no Chile que Touraine conheceu Adriana Arenas, com quem se casou alguns meses depois.
} 
América Latina, em particular o Brasil e o Chile, e que ela teve reflexos sobre os seus estudos, publicando vários livros e artigos sobre a região (Di Tella et al., 1966; Touraine, 1961, 1973, 1988). Isso nos permite afirmar que a sua obra, em particular a sua primeira fase, contém um diálogo, ainda que nem sempre direto, com a realidade latino-americana. As singularidades do processo de industrialização da região e a teoria da dependência, formulada por seus parceiros brasileiros e chilenos, o permitiu incorporar elementos novos em sua teoria geral.

Os contatos entre o grupo francês da sociologia do trabalho e a América do Sul se estabeleceram no contexto de expansão internacional das relações acadêmicas da sociologia. A criação de um novo domínio da sociologia no Brasil e no Chile que estudasse a indústria e o mundo do trabalho era parte não apenas da demanda por analisar e explicar a nova realidade latino-americana, impulsionada pela industrialização e a urbanização, mas também do projeto de ampliar a influência da "escola" francesa para além do velho continente. As relações estabelecidas no interior das associações, entidades e eventos internacionais, como a International Sociological Association (ISA) e a United Nations Educational, Scientific and Cultural Organization (Unesco), foram decisivas para a efetivação desta proposta (Festi, 2017).

Os primeiros contatos entre os brasileiros e Friedmann ocorreram na primeira metade da década de 1950, quando Anísio Teixeira, então presidente da Campanha Nacional de Aperfeiçoamento de Pessoal de Nível Superior (Capes), e Fernando de Azevedo, professor da cadeira II de Sociologia da Universidade de São Paulo (USP), planejaram impulsionar, com ajuda dos franceses, a sociologia industrial em São Paulo. Mas Friedmann só pôde visitar a cidade em 1958, momento em que ministrou um seminário na USP e sugeriu a criação 
do Centro de Sociologia Industrial e do Trabalho (Cesit), um laboratório que manteria contatos com o recém-criado LSI e com os jovens sociólogos Alain Touraine e Michel Crozier. ${ }^{17}$

Porém, antes da chegada dos franceses ao Brasil, um outro polo recém-criado da sociologia, o Instituto de Sociologia da Universidade do Chile, entrou em contato com Friedmann solicitando ajuda na criação de uma linha de pesquisa no campo da sociologia industrial. $\mathrm{O}$ velho sociólogo envia para esta missão Touraine, Reynaud e Brams, que levaram à frente, junto aos chilenos, uma pesquisa no período de 1956 a 1957. Juntou-se a eles o argentino Torcuato Di Tella, importante sociólogo em seu país ao lado de Gino Germani.

\section{Huachipato e Lota: o Chile enquanto objeto}

$\mathrm{O}$ objetivo do projeto de pesquisa era compreender, 84 por meio de pesquisas empíricas, observações de campo e aplicação de questionários, as funções e os papeis das categorias profissionais e as atitudes de dois diferentes grupos de operários em dois distintos meios de trabalho, ou seja, os mineiros, residentes em Lota, e os operários siderúrgicos, de Huachipato. Para execução da pesquisa, foram recrutados jovens universitários chilenos. Entre os participantes estava o estudante de história Enzo Faletto, que assim se recorda do trabalho que realizaram:

O primeiro estudo foi sobre os grupos de supervisores, que no Chile eram chamados de mayordomos de mira, ou capatazes. A ideia era acompanhar esse capataz em suas atividades e anotá-las, mas no fundo se tratava de

\footnotetext{
17 Encontramos nos arquivos de Florestan Fernandes diversas cartas de Crozier que comprovam sua vontade de vir à São Paulo, fato que nunca se concretizou. Cf. Fundo Florestan Fernandes. Acervo Coleções Especiais da Universidade Federal de São Carlos (Ufscar) em sua Biblioteca Comunitária (BCo).
} 
conhecer o mundo das minas, com o que me envolvi por quase três semanas [...] depois [...] fizemos entrevistas com os operários sobre a atividade. Touraine participou todo o tempo. Ele organizou a pesquisa e iniciou todo o trabalho de campo que levou, por fim, à elaboração dos questionários. Depois de Touraine veio, por meio do convênio, Reynaud, com quem iniciamos a análise e sobretudo a primeira parte da sistematização e da organização dos dados. (Rego, 2007, p. 192)

A conclusão das pesquisas em Lota e Huachipato, escrita por Touraine e Reynaud (Di Tella et al., 1966), 10 anos depois, deixa evidente uma aproximação com as teses da dependência para explicar a América Latina. Segundo os autores, a região teve uma industrialização com singularidades próprias, diferente do processo ocorrido na Europa. Dois fatores eram fundamentais: as relações de dependência desses países com os centrais, o que caracteriza uma autonomia limitada de seus sistemas nacionais de decisão, e a singularidade desse processo por mobilizar as massas populares enquanto força de transformação - e, por isso, as suas reivindicações teriam sido, ao menos parcialmente, reconhecidas. Isso terá certa implicação sobre o seu conceito de "sujeito histórico", pois na América Latina o antagonismo de classe não era tão evidente e não era o elemento central para definição do curso do movimento evolutivo da sociedade, como seria na Europa. Os operários latino-americanos teriam uma certa consciência do seu papel no desenvolvimento econômico e, portanto, o conceito de classe social seria insuficiente para a América Latina, sendo necessário a incorporação dos conceitos de nacionalismo e de desenvolvimento. Seria a articulação desses três elementos que permitiria compreender as orientações dos operários latino-americanos. 


\section{Um projeto inacabado no Brasil: industrialização e movimentos sociais}

O projeto do LSI "Mudança social e movimentos sociais na América Latina” era parte das investigações que compunham o eixo "Desenvolvimento econômico e movimentos sociais na América Latina”, conforme mostra o Quadro 1. Articulado em 1964, com Gino Germani, e colocado em prática no ano seguinte, ele foi um pretencioso projeto de cooperação entre pesquisadores de diversos países, que buscou realizar uma análise comparativa das escolhas econômicas (tipos de investimentos, formas de determinação dos salários, inflação etc.) dos atores sociais no processo de transformação da sociedade ou, para usar o vocabulário de Touraine, da manifestação do sistema de ação histórico. Segundo um outro relatório, o LSI visava, em colaboração com institutos de pesquisa latino-americanos, realizar um "certo número de enquetes sobre a formação das classes operárias, sobre os efeitos das imigrações internas, os movimentos sociais e nacionais, e sobre a formação dos dirigentes da classe econômica". ${ }^{18}$

As investigações seriam realizadas na Argentina, no Brasil, no Chile, no Peru, na Colômbia e no México. Isso exigia não apenas uma significativa articulação político-acadêmica, algo possível aos franceses num momento de relevantes aportes financeiros advindos de organismos nacionais e internacionais para os temas relativos ao desenvolvimento dos países do "terceiro mundo", mas sobretudo dependia das condições políticas de cada nação. Os golpes militares foram um dos principais limitadores na articulação dessa e de outras pesquisas. Mesmo assim, estiveram envolvidos na elaboração desse projeto os mais importantes centros

18 Cf. Laboratoire de Sociologie Industrielle. Rapport sur les activités de l'École Pratique des Hautes Études - VTe Section - concernant l'Amérique du Sud. Fonds Louis Vela : fonds de dossier sur l'Amérique Latine. Années 1960. Arquivos da EHESS, Paris. Código: CP9/72. 
de estudos sociológicos da América do Sul, ainda que nem todos tenham participado da sua concretização. ${ }^{19}$ Segundo um dos relatórios do LSI,

Os estudos que serão realizados na América Latina abordam um aspecto essencial deste programa: como a introdução, nos processos de decisão social, das categorias criadas pela industrialização, em relação tanto aos operários quanto aos dirigentes industriais, determinam as políticas econômicas, as vias sociais do desenvolvimento?
A formulação mesmo desta questão mostra que a orientação destas pesquisas é diferente de muitos trabalhos sociológicos, mais interessados pelas consequências ou pelas condições sociais da industrialização. Ao invés de situar primeiro uma sociedade em uma escala de crescimento ou de desenvolvimento e de pesquisar, em seguida, os atributos sociais desta situação econômica, queremos reconhecer a diversidade de caminhos do desenvolvimento e explicar a maneira pela qual cada sociedade combina os dois elementos fundamentais da industrialização: a submissão do presente ao futuro graças a uma taxa elevada de investimentos; a participação de uma parte crescente da população no controle e na utilização dos instrumentos e dos produtos do trabalho coletivo. ${ }^{20}$

19 Entre eles estão o Cesit, da USP, o Centro de Sociologia Comparada do Instituto
Torcuato Di Tella e o Instituto de Sociologia da Universidade de Buenos Aires, os
dois dirigidos por Gino Germani, o Departamento de Sociologia da Universidade
de Buenos Aires, dirigido por Garcia Rena, a Faculdade de Sociologia de Bogotá,
com ajuda de Fals Borda e Rotinof. O Centro Latino Americano de Pesquisa em
Ciências Sociais (Clapcs) do Rio de Janeiro, na época dirigida por Manuel Diegues,
chegou a manifestar interesse em participar da pesquisa, mas nada confirma a efe-
tivação desta parceria. Os documentos pesquisados levam a crer que a Fundação
Ford também colaborou financeiramente com o projeto.
20 Recherche sur les voies sociales de l'industrialisation en Amérique Latine, (Mimeo), p. 1.
Fonds Clemens Heller - Amérique Latine. Arquivos EHESS, Paris. Código: cpCH33. 
Como fica claro no texto anterior, as problematizações que colocavam o grupo de sociólogos em torno de Touraine coincidiam com as mesmas refletidas por uma parte da sociologia latino-americana, ou seja, as dificuldades do desenvolvimento econômico na periferia do capital. ${ }^{21}$ Os atores estudados - sejam os operários, sejam os industriais - eram compreendidos tanto como agentes do desenvolvimento quanto como defensores de interesses privados. Mas o elemento mais concreto desse estudo seria, afirma o documento, a investigação sobre a formação da consciência operária. Ela permitiria compreender o conjunto das formas pelas quais uma categoria profissional se torna um ator político e social, intervindo ativa ou passivamente nas decisões que afetam o desenvolvimento nacional.

As primeiras reuniões das equipes de pesquisa ocorreram ao longo do primeiro semestre de 1965, realizadas em Paris e Buenos Aires, com participação de Gino Germani. O LSI assumiria a maior parte dos custos do projeto, pagando as missões, os coordenadores e os pesquisadores. ${ }^{22} \mathrm{~A}$ pesquisa se efetivaria com a aplicação de questionários entre os operários - cerca de 800 a 1000 questionários por país - e a investigação em documentos relativos à atuação sindical, aos movimentos sociais e ao sistema político. As pesquisas foram realizadas entre novembro de 1965 e agosto de 1966, sem a participação da equipe brasileira, como mostrarei em seguida. O Brasil seria um dos principais países para a aplicação dessa pesquisa e a efetivação dessa relação

${ }^{21}$ O mesmo documento ressalta a importância da realização de estudos sobre os empresários, aspecto que não foi contemplado pelo projeto francês. No entanto, destacam, "felizmente a Cepal levou a frente um importante programa de pesquisa nesse domínio. Os trabalhos de F. H. Cardoso no Brasil e A. Lipman na Colômbia, já demonstram o interesse nesses estudos. F. H. Cardoso deve estender as suas pesquisas para o conjunto da América Latina" (Cf. Recherche sur les voies sociales de l'industrialisation en Amérique Latine, (Mimeo), p. 3).

22 Cf. Budget Amérique Latine de la VIe Section de l'EPHE (1963-1964). Fonds Clemens Heller - Amérique Latine. Arquivos da EHESS, Paris. Código: cpCH33. 
político-acadêmica de cooperação. Foi em São Paulo que, alguns anos antes, Touraine ajudou a criar o Cesit, um centro de pesquisa sobre o mundo da indústria e do trabalho que, desde a sua fundação, estabeleceu fortes laços acadêmicos e intelectuais com o LSI. Friedmann, quando veio ao Brasil no final dos anos 1950, viu no grupo de sociólogos da USP um potencial parceiro do novo laboratório que ajudou a criar na EPHE. Portanto, os primeiros anos do Cesit serviram para estreitar os laços pessoais e aprofundar as reflexões em comum em torno de temas como a classe operária, os empresários, a industrialização e o desenvolvimento, entre outros. ${ }^{23}$ A pesquisa que se iniciou em 1965 deveria concretizar esse projeto intelectual franco-brasileiro que vinha sendo preparado. No entanto, apesar da insistência e do desejo de Touraine, o Cesit acabou não participando da pesquisa. As razões para esse desfecho podem ser encontradas nas correspondências entre os intelectuais envolvidos, encontradas nos arquivos pessoais de Florestan Fernandes. ${ }^{24}$

Após sua defesa de doutorado, em junho de 1965, Touraine realiza uma nova viagem a Santiago do Chile onde se encontra com Fernando Henrique Cardoso, em exílio após o golpe militar no Brasil. Provavelmente, foi nesse encontro que ele se inteirou pela primeira vez da situação política no Brasil e das incertezas sobre o futuro do Cesit. Após deixar o Chile, Touraine ainda visitou o Brasil com o objetivo de convencer aqueles que ficaram em São Paulo a participarem da

\footnotetext{
${ }^{23}$ Cardoso fez seu primeiro intercâmbio para a França no final de 1962 e início de 1963, estagiando no LSI. Foi durante esta estadia que ele começou a escrever a sua tese de livre-docência sobre os empresários (defendida em 1963). Também passou por Paris, neste mesmo período, Octavio Ianni. Além dessas viagens, vale destacar as publicações de artigos de brasileiros na revista Sociologie du Travail, em particular no dossiê Ouvriers et syndicats d'Amérique Latine (1961), assim como as traduções para o português, um ano após as suas publicações em francês, dos dois volumes do Tratado de Sociologia do Trabalho (1962, 1963), organizados por Friedmann e Naville. ${ }^{24}$ Os arquivos de Florestan Fernandes estão guardados na Biblioteca da UFSCAR, no Acervo de Coleções Especiais. As correspondências a que nos referimos foram produzidas entre novembro de 1965 e outubro de 1966.
} 
pesquisa do LSI. Fernandes, que no momento assumiu a direção política do Cesit na ausência de Cardoso, estava no exterior. Coube, portanto, ao sociólogo francês, conversar pela primeira vez com Luiz Pereira e Leôncio Martins Rodrigues. ${ }^{25}$

Com Fernandes ausente durante sua passagem pelo Brasil, restou ao francês tentar convencê-lo por meio de cartas. Numa delas, mostrou-se preocupado com a situação política do Brasil: "em primeiro lugar, é possível realizar uma pesquisa por meio de entrevista neste momento?”, escreveu. Em seguida, caso fosse de interesse do Cesit, apresentou as condições para a efetivação do projeto no Estado de São Paulo, ou seja, a aplicação de questionários entre 900 e 1.000 operários e a pesquisa documental, como já descrevemos anteriormente ${ }^{26}$.

As dificuldades políticas não eram os únicos empecilhos para a efetivação desse projeto internacional. Do ponto de vista intelectual, a pesquisa do LSI coincidia com as aspirações e reflexões que vinham sendo feitas pelo grupo do Cesit. Numa carta a Fernandes, Cardoso, em viagem ao México, informa que havia avançado em seus estudos sobre o empresariado. Como pesquisador do Instituto LatinoAmericano de Planejamento Econômico e Social (Ilapes), órgão vinculado à Comissão Econômica para a América Latina e o Caribe (Cepal), ele estava encaminhando também uma pesquisa sobre a classe operária da Argentina e do Chile. "Além disso, o Leôncio deve ir a Santiago agora em janeiro para ajustar uma colaboração nova com o Cesit, sobre o mesmo tema. Por outro lado, o Weffort preparou um trabalho sobre 'desenvolvimento social e classes populares'”, escreveu Cardoso ${ }^{27}$.

25 Cf. Carta de Touraine a Florestan Fernandes. Paris, 17 de novembro de 1965. Fundo Florestan Fernandes. Acervo Coleções Especiais UFSCAR/BCo. Código: 02.09.0125 ${ }^{26}$ Cf. Carta de Touraine a Florestan Fernandes. Paris, 22 de dezembro de 1965. Fundo Florestan Fernandes. Acervo Coleções Especiais UFSCAR/BCo. Código: 02.09.0144.

27 Cf. Carta de Cardoso a Florestan. México, 1 de janeiro de 1966. Fundo Florestan Fernandes. Acervo Coleções Especiais Ufscar/BCo. Código: 02.09.1010. 
Nesse momento pós-golpe militar, tanto a Cepal quanto o clima intelectual cosmopolita instaurado em Santiago apareciam para os jovens membros do Cesit como meios oportunos para dar continuidade em suas carreiras acadêmicas e intelectuais. Cardoso, principal articulador do Cesit, encontrava-se agora envolvido com um projeto de enorme envergadura internacional, compondo uma equipe dirigida por José Medina Echevarría, num cargo de bastante prestígio. Apesar de Echevarría formalmente ser o supervisor de Cardoso, na prática ele havia entregue ao brasileiro a direção de todas as investigações. ${ }^{28}$

Esta ansiedade e preocupação com o futuro de suas carreiras pode ser captada na carta que Rodrigues enviou a Fernandes, de Santiago do Chile, em 14 de janeiro de 1966:

Touraine passou por SP e propôs-me a direção (para o Brasil) de uma pesquisa que pretende realizar na América Latina. $\mathrm{O}$ assunto, em princípio, me interessou porque está na área de minhas preocupações [...] No entanto, a verba que Touraine dispõe parece-me pequena para o tamanho do projeto, de modo que estou inclinado a não aceitar. Como a coisa parece ainda meio "verde", pretendo ir ganhando tempo. Em começos de março, quando voltar ao Brasil, discutirei o assunto com o senhor para tomar uma decisão definitiva. ${ }^{29}$

De fato, entre todos os membros do Cesit, Rodrigues era o que melhor havia desenvolvido uma pesquisa sobre a consciência e as atitudes operárias, tema de sua tese

28 A equipe era composta, segundo Cardoso, por jovens investigadores (sendo 1 chileno, 1 uruguaio, 1 argentino, 1 guatemalteco, 1 mexicano e 2 brasileiros - ele e Weffort). O posto que ocupava na Cepal era o mais alto na carreira profissional da ONU, recebendo 1.200 dólares mensais, livre de impostos, mais um adicional para a educação os filhos.

29 Cf. Carta de Rodrigues a Florestan Fernandes. 14 de janeiro de 1966. Fundo Florestan Fernandes. Acervo Coleções Especiais Ufscar/BCo. Código: 02.09.0337. 
de doutorado ainda não defendida naquele momento. Como na Cepal oferecia-se a oportunidade de continuar suas investigações em pesquisa semelhante a que fizeram no Cesit, preferia seguir os passos de Weffort e ir "ganhando tempo" com Touraine. No entanto, diferente da impressão de Rodrigues, a pesquisa do LSI estava bem madura e sendo realizada em outros países. Com a possibilidade de uma verba complementar para a pesquisa no Brasil, Touraine tentou ganhar para o projeto Luiz Pereira, na época diretor do Cesit. Para isso, escreveu cartas a ele e novamente a Fernandes, que concordou que Pereira era um pesquisador perfeitamente qualificado para participar do projeto. No entanto, talvez devido ao valor oferecido para esse trabalho, ${ }^{30}$ Pereira também acaba recusando a oferta.

Em carta, Fernandes parece ter argumentado que Pereira estava atribulado demais com outras tarefas, dentre elas a direção do centro, para assumir a coordenação da pesquisa do LSI no Brasil. Em resposta, Touraine reconhece que o "desenvolvimento intelectual de bons pesquisadores pode ser ameaçado pelo peso dos trabalhos coletivos e das responsabilidades de todas as ordens", e complementa: "eu acredito que o mais sábio é esperar. Meu desejo de participar de pesquisas no Brasil segue vivo, mas sempre busco associar de uma maneira igual pesquisadores de meu grupo com pesquisadores de instituições nacionais". ${ }^{31}$ A questão seria retomada em conversa pessoal numa viagem que Touraine faria ao Brasil em breve, mas que, por conta de vários adiamentos e do endurecimento

\footnotetext{
${ }^{30}$ Touraine propôs de imediato o pagamento de 1.200 dólares a Pereira pela colaboração no projeto, mais outra soma um pouco acima desta para o trabalho de campo (Cf. Carta de Touraine a Luiz Pereira. 20 de julho de 1966. Fundo Florestan Fernandes. Acervo Coleções Especiais UFSCAR/BCo. Código: 02.09.0143).

31 Cf. Carta de Touraine a Florestan Fernandes. 23 de agosto de 1966. Fundo Florestan Fernandes. Acervo Coleções Especiais Ufscar/BCo. Código: 02.09.0142.
} 
da ditadura, nunca ocorreu, impossibilitando a continuidade da relação entre o LSI e o Cesit, sonhada no início dos anos 1960 .

\section{Conclusão}

Neste artigo busquei demonstrar que a primeira fase da produção intelectual de Touraine foi também, como ele mesmo reconheceu em entrevista concedida a mim, um período de formação enquanto sociólogo, a partir dos embates teóricos travados e, sobretudo, das pesquisas empíricas. $\mathrm{O}$ novo estilo de investigação criado pela geração de sociólogos do pós-guerra teve como princípio o trabalho de campo com a aplicação de questionários para medir e quantificar as atitudes de grupos sociais e a observação participante. Com enormes aportes financeiros advindos de organismos nacionais e internacionais "modernizadores", foi possível exportar essa tradição sociológica para outros países, influenciando grupos e centros de pesquisa, como foi o caso do Brasil, por meio da comunidade acadêmica internacional estabelecida nesse período.

Touraine não foi apenas um dos mais importantes representantes deste novo estilo de pesquisa, como foi além dele, usando-se dos métodos estabelecidos para alimentar novas problemáticas e perspectivas de abordagens sobre o mesmo objeto, o mundo do trabalho e da indústria. Suas preocupações, desde os seus primeiros estudos nas fábricas Renault até os dos estudantes em maio de 1968, se pautaram em explicar os conflitos sociais desde a perspectiva das experiências dos atores envolvidos. Dessa forma, a modernidade ia sendo definida enquanto uma época em que os sujeitos históricos tinham consciência de sua capacidade de criar a própria sociedade. Esse conjunto de questões alimentaram aquilo que viria a resultar em sua proposta de teoria geral expressa nos livros Sociologie de l'action (1965) e Production de la Société (1973). 


\section{Arquivos pesquisados:}

Acervo Coleções Especiais da UFSCar.

Arquivos da EHESS, Paris.

Arquivos da OCDE, Paris.

Arquivos Nacionais da França, Paris.

\section{Entrevistas:}

Alain Touraine, 22/02/2017

Fernando Henrique Cardoso, 06/12/2017

\section{Ricardo Colturato Festi}

é doutor em Sociologia pelo Instituto de Filosofia e Ciências Humanas (IFCH) da Universidade Estadual de Campinas (Unicamp) com a tese intitulada O Mundo do Trabalho e os Dilemas da Modernização: percursos cruzados da sociologia francesa e brasileira (1950-1960). Estágio de pesquisa (doutorado sanduíche) na École des Hautes Études en Sciences Sociales, Paris (EHESS), 2015-2017. Professor de Sociologia do Cotil-Unicamp. Membro do Grupo de Pesquisa "Mundo do Trabalho e suas Metamorfoses", coordenado pelo prof. Ricardo Antunes. Têm experiências nas áreas de Sociologia, com ênfase em Sociologia do Trabalho e Pensamento Social.

\section{Bibliorafia}

BRAERMAN, Harry. 1987. Trabalho e capital monopolista a degradação do trabalho no século XX. 3a. ed. Rio de Janeiro: LTC.

DI TELLA, Torcuato et al. 1966. Huachipato et Lota: étude sur la conscience ouvrière dans deux entreprises chiliennes. (Recherche menée par l'Institut de recherches sociologiques de l'Université du Chili). Paris: Éditions du Centre National de la Recherche Scientifique.

DOFNY, Jacques et al. 1966. Les ouvriers et le progrès technique. Étude de cas: un nouveau laminoir. Paris: Armand Colin.

FESTI, Ricardo Colturato. 2017. A primeira geração de sociólogos do trabalho no Brasil (1950/60) e seus diálogo com a "escola" francesa. Paper apresentado no XVIII Congresso Brasileiro de Sociologia. Brasília, DF, 26 a 29 de julho. Disponível em: http:/ / bit.ly/2CZhOpe. Acesso em: 8 mar. 2019. 
FESTI, Ricardo Colturato. 2018. O mundo do trabalho e os dilemas da modernização: percursos cruzados da sociologia francesa e brasileira (1950-1960). Tese de Doutorado em Sociologia. Campinas: Unicamp. Disponível em: http:/ /bit.ly/2G1sJQf. Acesso em: 9 mar 2019.

FRIEDMANN, Georges. 1946. Problèmes humains du machinisme industriel. Paris: Gallimard.

FRIEDMANN, Georges. 1963. Où va le travail humain ? Paris: Gallimard. FRIEDMANN, Georges. 1956. Le travail en miettes : spécialisation et loisirs. Bruxelles: Éditions de l'Université de Bruxelles.

FRIEDMANN, Georges; NAVILLE, Pierre. 1961. Traité de sociologie du travail. Paris: Armand Colin.

LE LABORATOIRE DE SOCIOLOGIE INDUSTRIELLE. 1966. Paris: EPHE, Laboratoire de sociologie industrielle.

LE LABORATOIRE DE SOCIOLOGIE INDUSTRIELLE. 1969. Paris: EPHE, Laboratoire de sociologie industrielle.

LE LABORATOIRE DE SOCIOLOGIE INDUSTRIELLE DE L'ECOLE pratique des Hautes Etudes. 1960. VIe section. Revue française de sociologie, v. 1, n. 2, pp. 218-219.

NAVILLE, Pierre. 1961. L'automation et le travail humain : rapport d'enquête (France, 1957-1959). Paris: Centre national de la recherche scientifique.

NAVILLE, Pierre. 1963. Vers l'automatisme social? Problèmes du travail et de l'automation. Paris: Gallimard.

RODRIGUES, Leôncio Martins. 1966. [Correspondência]. Destinatário: Florestan Fernandes. Santiago, 14 jan.

REGO, José Marcio. 2007. Entrevista com Enzo Faletto. Tempo Social, v. 19, n. 1, pp. 189-213. 6 Jun. 2007.

ROETHLISBERGER, Fritz Jules. 1941. Management and morale. Cambridge, Massachusetts: Harvard University Press.

TANGUY, Lucie. 2017. A sociologia do trabalho na França: pesquisa sobre o trabalho dos sociólogos (1950-1990). Tradução Estela dos Santos Abreu. São Paulo: Edusp.

TOURAINE, Alain. 1952. Ambiguïé de la sociologie industrielle Américaine. Cahiers Internationaux de Sociologie, v. 12, pp. 131-146. TOURAINE, Alain. 1955. L'Evolution du travail ouvrier aux usines Renault. Paris: Centre national de la recherche scientifique.

TOURAINE, Alain. 1961. Industrialisation et conscience ouvrière à

São-Paulo. Sociologie du Travail, v. 3, n. 4, pp. 77-95.

TOURAINE, Alain. 1973. Vie et mort du Chili populaire: journal sociologique, juillet-septembre 1973. Paris: Éditions du Seuil.

TOURAINE, Alain. 1977. Un désir d'Histoire. Paris: Stock. 
Um desejo de história

TOURAINE, Alain. 1988. La parole et le sang: politique et société en Amérique Latine. Paris: Odile Jacob.

TOURAINE, Alain.; RAGAZZI, Orietta. 1961. Ouvriers d'origine agricole.

Paris: Éditions du Seuil.

TOURAINE, Alain.; VERLEY, Étienne. 1949. Enquête française de sociologie industrielle. Cahiers Internationaux de Sociologie, v. 7, pp. 109-121. 


\section{UM DESEJO DE HISTÓRIA: A SOCIOLOGIA DO TRABALHO DE ALAIN TOURAINE (1948-1973)}

\section{RICARDO COLTURATO FESTI}

Resumo: Este artigo buscará problematizar a primeira fase da produção teórica de Alain Touraine, que estende-se do seu estudo sobre as fábricas Renault (1948) à publicação de Production de la Société (1973). Durante essa fase, o autor desenvolveu inúmeros e extensos programas de pesquisas empíricas sobre o mundo da indústria e do trabalho tendo como uma de suas preocupações centrais a problemática da consciência operária. Destacaremos a importância dessas pesquisas, pouco conhecidas pelo público acadêmico, assim como a relação que Touraine estabeleceu com a América Latina - em particular o Brasil e o Chile - na formação de sua teoria sociológica. Visa-se mostrar que a teoria que o autor produziu nessa fase buscou responder à necessidade de uma suposta modernização da sociedade ocidental, fosse ela o centro ou a periferia.

Palavras-chave: Sociologia do Trabalho Francesa; Sociologia do Trabalho Brasileira; Alain Touraine.

\section{A DESIRE FOR HISTORY: ALAIN TOURAINE'S SOCIOLOGY OF WORK (1948-1973)}

Abstract: This article will seek to problematize the first phase of Alain Touraine's theoretical production, from his study on the Renault factories (1948) to the publication of Production de la Société (1973). During this phase, the author developed numerous and extensive empirical research programs on the world of industry and work, and had the problem of worker consciousness as one of his central concerns. We will emphasize the importance of these studies, little known by the academic public, as well as the relationship that Touraine established with Latin America, in particular Brazil and 
Chile, in the formation of his sociological theory. We will try to show that the theory that the author produced in this phase sought to respond the need for a supposed modernization of Western society, whether the center or the periphery.

Keywords: French Sociology of Work; Brazilian Sociology of Work; Alain Touraine.

Recebido: 06/04/2018Ａprovado: 25/02/2019 